$12-21-2021$

\title{
Dossier: Genocide Research-Some Observations and Some Suggestions
}

Christian Gudehus

Ruhr-Universitat Bochum

Follow this and additional works at: https://digitalcommons.usf.edu/gsp

\section{Recommended Citation}

Gudehus, Christian (2021) "Dossier: Genocide Research-Some Observations and Some Suggestions," Genocide Studies and Prevention: An International Journal: Vol. 15: Iss. 3: 24-32.

DOI:

https://doi.org/10.5038/1911-9933.15.3.1872

Available at: https://digitalcommons.usf.edu/gsp/vol15/iss3/7

This Dossier is brought to you for free and open access by the Open Access Journals at Digital Commons @ University of South Florida. It has been accepted for inclusion in Genocide Studies and Prevention: An International Journal by an authorized editor of Digital Commons @ University of South Florida. For more information, please contact digitalcommons@usf.edu. 


\title{
Dossier: Genocide Research- Some Observations and Some Suggestions
}

\author{
Christian Gudehus \\ Ruhr-Universität Bochum \\ Bochum, Germany
}

\begin{abstract}
Introduction ${ }^{1}$
Genocide research is a firmly established field. Not only are International Association of Genocide Scholars (IAGS) and International Network of Genocide Scholars (INoGS) two international organizations in the field, but there are also a variety of networks that concern themselves with aspects of collective violence and therefore deal with similar topics as genocide research. Having edited GSP for a considerable number of years and being a researcher in the field, I have been observing various movements and tendencies. Many of these are innovative as well as stimulating and promote the understanding of this particular form of collective violence. As much as it is important to further deepen and distribute this knowledge, so do constructive criticism and having a clear view especially on methodological, epistemological, and basic theoretical developments in the field-these are aspect which are necessary to me. In this Dossier, I focus only on some selected aspects I consider problematic and make a first attempt at roughly sketching some proposals of how these challenges can be met.
\end{abstract}

\section{Borrowing}

A comprehensive understanding and explanation of genocidal processes and their consequences can only be achieved if research findings of different disciplines are taken into account. Especially in the context of mass violence; frequently, the explanation of individual and collective action makes it necessary to draw on disciplines or approaches that explain human actions-for example, social psychology, psychoanalysis, or social theories of a sociological provenance or action theories. When researchers, such as historians or criminologists, integrate information taken from other disciplines than their own into their narrative, Jovan Byford and Cristian Tileagă call this borrowing. ${ }^{2}$ Using the example of a study on German WWII soldiers, they aptly showed that the authors "simplified psychology: they borrowed a basic concept of 'frames of reference,' stripped it of its ontological and epistemological complexity, and applied it, in a matter-of-fact way, to historical material. The central issue here is that interdisciplinarity, if it is to offer genuine insights, must strive to complicate rather than simplify things." 3 Borrowing, also according to Byford and Tileagă, is also selective and tends to serve as confirmation of one's own assumptions. ${ }^{4}$ In genocide research of many provenances, references to sociopsychological experiments that, for the most part, were carried in the USA between the 1950s and 1970s, are common. They are used to prove the so-called situationalism, according to which behavior can best be explained by predominantly accounting for the situational constellation. Despite a comprehensive body of critical literature, these experiments are rarely

\footnotetext{
${ }^{1}$ The views expressed in this Dossier belong solely to the author. Due to their ongoing nature, Dossiers do not undergo the double-blind peer review process.

2 Jovan Byford and Cristian Tileagă, "Social Psychology, History, and the Study of the Holocaust: The Perils of Interdisciplinary 'Borrowing,'” Peace and Conflict: Journal of Peace Psychology 20, no. 4 (2014), advance online publication, 349-364, accessed November 1, 2021, http:// dx.doi.org/10.1037/pac0000054.

${ }^{3}$ Ibid., 360.

${ }^{4}$ Ibid.
}

Christian Gudehus. "Dossier: Genocide Research-Some Observations and Some Suggestions." Genocide Studies and Prevention 15, no. 3, 24-32. https://doi.org/10.5038/1911-9933.15.3.1872.

(c) 2021 Genocide Studies and Prevention. 
historicized or contextualized. ${ }^{5}$ To this day, the continuously growing critical literature on classic studies such as the so-called Milgram Experiment or the, as regards its execution, highly problematic Stanford Prison Experiment remains largely ignored-with the exception of specific secondary literature on these studies. This also applies to the question of how far such historically and culturally specific studies can be transferred to other historical and cultural contexts. Experimental research faces a number of fundamental problems of which two examples will be sketched out here: First, comprehensive comparative studies have shown that many experiments could not be successfully (i.e. with the same result) replicated. ${ }^{6}$ Second, and as has been mentioned above, the participants in many studies that have been used to draw generalizing conclusions, are not representative but "do occupy the extreme end of the distribution."7 Consequently, such studies can only be quoted with considerable reservation when generalizing statements on individual behavior in contexts of collective violence are made.

This deficient contextualization has indeed, I believe, to do with an insufficient perusal of the relevant literature. It stands to reason that perhaps the studies themselves are read but that their criticism is not sufficiently accounted for. Additionally, there are examples for references which unequivocally show that even the original study itself has not been wholly studied or even been studied only second hand. When research quotes Solomon E. Asch's studies to prove the so-called thesis of conformity according to which people act against their own perception in order to align themselves with a majority, for example, it still often does so in a biased and undifferentiated fashion. People who act like this do actually exist, but in Asch's experiments this is, first of all, not the majority of participants. Second, Asch carried out interviews and found that a number of different types of motivations led to the respective individual modes of behavior. Third, Asch limits the transferability of the results to contexts beyond the laboratory in many respects. ${ }^{8}$ It is therefore questionable to cite Asch in order to prove the applicability of the conformity thesis in the context of individual actions in genocidal events.

In short, a detailed consultation of relevant research studies is necessary especially when the aim is to prove an often one-dimensional thesis. This applies to their epistemological presuppositions that differ, for example, between experimental social psychology and historical science. ${ }^{9}$ It is also necessary to consult the relevant secondary literature extensively. All this may sound banal and even seem needless to say-yet, a look into the majority of publications on the complex group of themes making up genocide research illustrates how little these standards are taken heed of. ${ }^{10}$

5 On Milgram: Gina Perry, Behind the Shock Machine: The Untold Story of the Notorious Milgram Psychology Experiments (New York: The New Press, 2013); About the SPE: Thibault Le Texier, "Debunking the Stanford Prison Experiment," American Psychologist 74, no. 7 (2019), 823-839.

${ }^{6}$ A huge collaborative effort that replicated 28 studies with more than 15,000 participants in 36 countries led to comparative results. Richard A. Klein et al., "Many Labs 2: Investigating Variation in Replicability Across Sample and Setting," Advances in Methods and Practices in Psychological Science 1, no, 4 (2019), doi: $10.1177 / 2515245918810225$.

7 Joseph Henrich, Steven J. Heine, and Ara Norenzayan, "The Weirdest People in the World?" Behavioral and Brain Science 33, no. 2-3 (2010), 61-83.

8 Solomon E. Asch, "Studies of Independence and Conformity: I. A Minority of One Against a Unanimous Majority," Psychological Monographs: General and Applied 70, no. 9 (1956), 1-70.

9 Ivana Marková, for example, pointed out that "social psychology does largely aim at inductive generalizations" meaning, "it treats populations as aggregates of independent individuals rather than as groups in which individuals are related to one another in terms of psychological features." Whereas historical thinking is the "capacity of weaving together concepts and propositions" that "is guided by intuition and/or judgement, which are features of natural, rather than formalistic thinking." Ivana Marková, "Questioning Interdisciplinarity: History, Social Psychology, and the Theory of Social Representation," in Psychology and History: Interdisciplinary Explorations, ed. Christian Tileagă and Jovan Byford (Cambridge: Cambridge University Press, 2014), 113.

${ }^{10}$ Christian Gudehus, "Appropriations of Social Psychological Studies in Genocide Research Exemplified by References to Solomon E. Asch's Study of Independence and Conformity," Journal of Genocide Research, doi:10.1080/14623528.2021.1987039. 
To put this clearly, I am not making a case against the adoption of knowledge from other fields of research. As a matter of fact, not enough is actually taken on especially when it concerns social theoretical approaches. Social theory occupies itself with action, social orders, and their change. ${ }^{11}$ These are integral topics of genocide research. Unfortunately, works on social norms, roles, or processuality are not sufficiently studied in the Anglo literature on genocidal violence. ${ }^{12}$ It thus happens, for example, that perpetrator is called a social role which is arguable because roles are, amongst other features, defined as a cluster of expectations. Hence father, superior, and class clown are undoubtedly social roles. There are notions and expectations how these should be occupied. Perpetrator, however, is a category constructed ex-post and designates people who have carried out actions that can be interpreted as participations in genocidal violence. There is, furthermore, an extensive sociological but also psychological body of literature on social norms, their evolution, consolidation, regression, and change. Such works should be studied more intensively and, of course, in a more detailed fashion. The above are only examples illustrating that it is not necessary to reinvent the wheel. Instead, already acquired knowledge should be circulated and find its way into explanatory models. I do not say this would never happen-yet I say that it happens far too little.

\section{Data Documentation}

Dialogue between the disciplines and approaches (for example, between psychology and cultural psychology) is necessary. An important condition for this is that also the social sciences and humanities develop standards for the collection, documentation, analyses, and publication of data. Such standards furthermore promote the transparency and consequently the comprehensibility of conclusions drawn from the data; and finally, especially European funding institutions increasingly demand that the data collected in research projects should be published. Likewise, the European Union, for example, demands open-access publication. I agree that studies (directly or indirectly) financed primarily by taxes should be made available to the community but also the public in general free of charge.

Accordingly, I propose that especially interview material (here chosen as an example for diverse types of data used in empirical research) should be made available in two ways. Since many journals (and books) by now are published online and are open access, the publication of the data on which the studies are based on is financially unproblematic. Therefore, publishers and editorial boards should, for example, encourage their authors to make complete interviews accessible and facilitate this. Of course, it must be warranted that no disadvantages concerning the interviewees result from this-they must be protected if necessary. Hence, the publication of interviews should not be mandatory yet possible. It would also be an option to modify the material in such a way that the interviewees' rights and personal security are protected. Furthermore, it would make sense to set up a curated data base. Probably thousands of interviews with people who have experienced (suffered, executed, witnessed, heard of etc.) genocidal violence exist. Making this data available has a whole array of advantages:

- The quality (and authenticity) of data can be secured.

- The generation of data can be contextualized.

- In many cases, it will be possible to identify people that have been repeatedly interviewed by different agents at different

\footnotetext{
${ }^{11}$ Hans Joas and Wolfgang Knöbl, Social Theory: Twenty Introductory Lectures (Cambridge: Cambridge University Press, 2009).

12 On social norms, for example Heinrich Popitz, "Social Norms," Genocide Studies and Prevention 11, no. 2 (2017), 3-12, accessed October 5, 2021, http://doi.org/10.5038/1911-9933.11.2.1552; On social roles: Heinrich Popitz, "Der Begriff der sozialen Rolle als Element der soziologischen Theorie," in Heinrich Popitz Soziale Normen, ed. Friedrich Pohlmann (Frankfurt am Main: Suhrkamp, 2006), 117-157; On processuality: Andrew Abbott, Time Matters: On Theory and Methods (Chicago: The University of Chicago Press, 2001).
} 
times. A systematic comparison of such interviews might yield unexpected findings.

- It might be that many questions can be answered by drawing on data already gathered so that the focus on further studies can be on groups of topics that have not been covered by the studies in which this data had originally been collected.

- Researchers with few resources can participate in research by using the documented interviews. This promotes a diversity of perspectives.

- Comparisons can be considerably simplified-trends and particularities can be uncovered by employing (partially) automated methods of evaluation.

To sum up, positive results concerning the accessibility of data, its quality, transparency (concerning its interpretation), its comparability, and the chance to analyze large data amounts are expectable outcomes.

\section{Translations}

Still, a large part of the research in the field is done by researchers from Europe, North America, and Australia. Only a minority of studies that investigate cases beyond these regions can attest a thorough command of the languages spoken there and a thorough knowledge about the specific features of these cultures. Culture does not only comprise history but also includes concepts of identity, mentalities, life scripts-hence, quite fundamentally, forms of sedimented experiences. ${ }^{13}$ The transfer of psychological insights between very diverse cases (as regards time, space, culture) indeed are but one example for this deficit.

The role of translators has as yet not been adequately addressed in many publications. This applies to the process of data generation (for example, in interviews or reading processes) but also to the analysis of such data. Only rarely are translators considered important agents participating in the research process-and even more rarely are they actually named. In the analytic process, there is a lack of extensive reflections about the requirements, the necessary abilities (vs. formal qualifications), and the roles such people play. There are thus studies in which far reaching conclusions are based on translators' ad-hoc translations. It is understandable that such a course of action cannot always be avoided. However, if conclusions are reached based on such data, this must be transparently and critically discussed.

The role of translators and interpreters of language and culture as well as the roles of other agents participating in the research process must thus be laid open and subject to deliberation. Further, if there is a chance that the validity of statements is influenced by their translations, this requires special attention. If possible, translators should then be incorporated into the analysis of data and, if appropriate, be mentioned as co-authors.

\section{Sources}

For a long time, genocide research was based on information obtained in legal processes. In the last couple of years, an increasing number of interviews especially with individuals who executed violence (usually referred to as perpetrators) have been conducted. Further videos available online have been becoming more relevant for the analysis of specific, very local events of violence. As a matter of fact, though, there are cases of violence which are definitely of genocidal nature that are hardly documented at all or for which very few sources can be made available. Thus, Chinese state violence against Falun Gong, Tibetans, and Uighurs are enormous challenges for genocide research. Not only there are government agents who control the access to and distribution of information in China itself. These are moreover engaged in order to

\footnotetext{
${ }^{13}$ Christian Gudehus, "On the Significance of the Past for Present and Future Action," in Theorizing Social Memories:
} Concepts and Contexts, ed. Gerd Sebald and Jatin Wagle (London, New York: Routledge, 2016), 84-97. 
smother all discussion in this regard abroad from China. This applies just as much to propaganda as it is, for example, distributed by the so-called Confucius Institutes (in Germany) as to political threats, often communicated via diplomatic channels, but also to specific threats meant to intimidate individuals (as has been mentioned, abroad from China). ${ }^{14}$ Taken together, these challenges render it very difficult for researchers to collect information. Second, for example editors of academic journals can hardly verify data and interpretations. It is further frequently the case that many of those who have access to information have no academic background or at least are not experts in the field of genocide studies. Because of this, their contributions are regularly rebuked in the course of the usual review processes. It is hence necessary that, first of all, journals must provide room (for example, special columns) for such texts that are often rich in documentations, yet rather poor as regards theories. Second, to those who research in the field other criteria, for example as regards the allocation of stipends, should apply than to those who follow the conventional paths. This would make sense because in these cases it is not the individual academic development that is at stake but rather the acquisition of information that can feed academic discourse. Third, such agents need special support by editorial boards. Fourth, and returning to the issues of sources, it is important to accept new types of sources and to consider in some special cases whether it might not make sense to accept information for publication even if not everything can be verified in much detail. An example for such special sources that are unfortunately difficult to verify are screenshots from messenger-exchanges as used by Rukiye Turdush and Magnus Fiskesjö in their Dossier for GSP. 15

\section{Canonization}

If authors, studies, concepts, approaches but also data (for example, numbers of victims) are referred to exceptionally often in the literature, I understand these to be canonized. It is also this process of selection and some of the problems related to it that I would like to focus on. First of all, problematic is whatever prevents an adequate description of the object of investigation at hand. These are, to begin with, data, numbers for example, that are hardly ever subject to critical investigation and that therefore are basically distributed by being copied. Hence, often not so much the process itself or the existence of a canon is the problem, but rather the all too frequently occurring uncritical adoption of canonized information. I have already explained the above with reference to the example of borrowing. Accordingly, with reference to Solomon Asch, conformity is pointed out to be an important feature of genocidal events although Asch himself limited the scope of his research at several levels. This applies, for example, to the fact that the observation, measurement, and labelling of a particular mode of behavior does not explain it.16 As Rob Bond and Peter Smith suggest, it would thus have been possible to write about tactfulness or social sensitivity instead. ${ }^{17}$ Additionally, such terms-if used as buzz words and canonized references-can simply not pay justice to the processual nature of human activity as such. Even though this processual

14 "Out of Sight, Not out of Reach. The Global Scale and Scope of Transnational Repression. Case Studies: China," Freedom House, accessed October 27, 2021, https://freedomhouse.org/sites/default/files/2021-02/ FH TransnationalRepressionReport2021 rev020221 CaseStudy China.pdf; "China: Revoke Sanctions on International Scholars and Respect Free and Open Scholarly Inquiry," Scholars at Risk, accessed November 7, 2021, https:// www.scholarsatrisk.org/2021/05/ china-revoke-sanctions-on-international-scholars-and-respect-free-andopen-scholarly-inquiry /; On the Konfuzius-Institute in Germany: Katrin Büchenbacher, "Universitäten brauchen China-Kompetenz, keine Konfuzius-Institute," Neue Zürcher Zeitung, October 27, 2021, accessed October 27, 2021, https:/ / www.nzz.ch/meinung/europaeische-universitaeten-brauchen-keine-konfuzius-institute-ld.1652328? mktcid=nled\&mktcval=164 2021--10-28\&kid=nl164 2021-10-27\&ga=1\&trco=.

${ }^{15}$ Rukiye Turdush and Magnus Fiskesjö, “Dossier: Uyghur Women in China's Genocide," Genocide Studies and Prevention 17, no. 1 (2021), 22-43, accessed November 13, 2021, https:/ / doi.org/10.5038/1911-9933.15.1.1834.

16 Asch, Studies, 51.

${ }^{17}$ Rob Bond and Peter B. Smith, “Culture and Conformity: A Meta-Analysis of Studies Using Asch's (1952b, 1956) Line Judgment Task," Psychological Bulletin 119, no. 1 (1996), 126. 
quality is often referred to, it has hardly ever been captured as aptly as Thomas Hoebel and Wolfgang Knöbl did when writing about the integral conditions of all cognitive and explanatory processes. ${ }^{18}$

Finally, despite the enormous broadening of the field and the search for new cases, considerable gaps exist. For example, since its move to publish online in 2013, only two papers were submitted to GSP that dealt with the already mentioned mass persecution of several groups by the Chinese government. ${ }^{19}$ For this reason, I once more would like to appeal to lecturers, researchers, funding agencies, and in particular to the relevant organizations that they should create the necessary conditions for this type of research. ${ }^{20}$ This begins with education in this field that in many cases relies too heavily on a canon of cases and that does not address the question how knowledge about cultures and of languages can be taught that would enable researchers to explore new fields. It must become attractive for academics to approach cases that have not been canonized and that are difficult to research. The cooperation with faculties, departments, and institutions beyond genocide research that are familiar with and know how to access the materials necessary for research is urgently needed. It is also worthwhile to pay more attention to research subsumed under the label citizen science that has recently attracted increasingly more attention. In short, it is important to put the competences of non-academic agents to use for the research process. Examples for this are data collection projects such as the one on the Dersim genocide between 1937 and 1938. Committed citizens conducted nearly 400 professional interviews in languages of which some are only spoken by few people as, for example, in Zazaki. Also, the transcriptions of the material and the translation of languages that spoken outside this community (or only by their descendants) can only work if the close cooperation with citizens who have the corresponding competences is sought.

At a very basic level the sparse number of theories, concepts, and approaches is worrying even if every now and then individual agents in the field manage to overcome this problem. However, systematic projects such as the documentation, exploration, and perhaps also the application of so-called indigenous psychologies are as yet lacking. I have already pointed out above the, so to speak, culture-insensitive and ahistorical approaches that are typical for some disciplines. There is a large number of alternative approaches still waiting to be put to the test that are still unheard of in genocide research in the English-speaking world. It will not be easy to overcome this obstacle because today's academic establishment with its measurement methods (such as the impact factor) and the growing weight of administrative issues leaves little room for exploration. Accordingly, it is individual agents that, for example,

18 Thomas Hoebel and Wolfgang Knöbl, Gewalt erklären! Plädoyer für eine entdeckende Prozesssoziologie (Hamburg: Hamburger Edition, 2019).

19 Maria Cheung et al., "Cold Genocide: Falun Gong in China," Genocide Studies and Prevention 12, no. 1 (2018), accessed October 5, 2021, https://doi.org/10.5038/1911-9933.12.1.1513; Turdush and Fiskesjö, Dossier: Uyghur Women in China's Genocide. The lack of work on China, for example, is also noted by Jeff Benvenuto in his review of Cultural Genocide: Law, Politics, and Global Manifestations in this issue, see Jeff Benvenuto, "Book Review: Cultural Genocide: Law, Politics, and Global Manifestations," Genocide Studies and Prevention 15, no. 3, 131-134, https://doi.org/ 10.5038/1911-9933.15.3.1862. One of the few positive examples of articles on China's genocidal politics in Journals that deal with Genocides is Joanne Smith Finley, "Why Scholars and Activists Increasingly Fear a Uyghur Genocide in Xinjian," Journal of Genocide Research 23, no. 3 (2021), accessed November 13, 2021, https://doi.org/ 10.1080/14623528.2020.1848109. Smith Finley, by the way, writes that the "word 'genocide' [is] unqualified by the modifier 'cultural'" - but this is a different discussion.

${ }^{20}$ Incidentally, it is interesting in this context that of the 11 resolutions documented on the IAGS website, none deals with China (though four alone deal with the Armenian genocide). See, "Resolutions," International Association of Genocide Scholars (IAGS), accessed November 7, 2021, https:/ /genocidescholars.org/publications/resolutions/. 
strive to adapt indigenous psychologies or something like cultural psychology so that they can be used in genocide research. ${ }^{21}$

A very general problem in all research is the tendency to attach too much importance to the label of the object of investigation. This may sound absurd since, for example, it is indeed the declared aim of all memory studies to investigate remembrance. The same applies to the investigation of collective violence or genocides. At the same time, though, the conceptualization of various events, practices, and social relations in the context of a genocide constitutes epistemic frames that guide understanding. As soon as something is labelled a genocide, often the corresponding explanatory narratives follow that, at the core, are based on an established vocabulary and a likewise fashionable argumentation. To me, this seems to be one of the strongest drivers of canonization.

\section{Academic Culture}

The academic generation of knowledge is based on transparency and criticism. In contrast to, for example, ideologies, research continuously reforms itself. This does not happen without resistance, fights, and unfortunately not without victims-for example those whose careers were finished because of their opinions. At the same time, it is especially innovation that opens up new spaces, approaches, and career paths. Currently, diversity and decolonization are such sets of issues that, on the one hand, are much debated and, on the other, career promoters. So, there are movements. What receives too little attention in academic discourse and practices is the systematic recognition of failure. It is exactly this is what is meant by practiced transparency. Yet in some areas of psychology, researchers calculate and adjust for as long as it takes to come up with significant and unequivocal results. Results that, in the worst case, are adopted by other disciplines and are there used as the basis for explanatory models. Very rarely we read about unusable data, about equivocal translations, about opacities that cannot be cleared up, about failed interviews or about the event that at the end of a research process no well-founded and perhaps far-reaching results can be announced. There are reasons for this that are related to funding (e. g. grants, scholarships), possibilities to be published, and jobs, hence to career options of a very fundamental nature. This is not going to be changed overnight. Also, national academic cultures and also cultures of the various disciplines vary considerably. What we as individuals can do nonetheless, is to make room for failure and therefore for transparency when it comes to teaching and to supervising students and PhDs or when we work as reviewers, authors, and editors. This is also an appeal to individuals, thus addressing the respective individual scopes.

Criticism is fundamental to scientific insights and will remain so, too. As a matter of fact, a large part of criticism does not take place on the public stage but, for example, in the context of review processes. In peer-review-processes, (the often constructive, but also sometimes harsh and not always fair) criticism leads to improvements but also to conformity as regards style, structure, and wording. Authors-and I say this in my capacity as the editor of a journal-tend to be at the mercy of reviewers and editors. They depend on their integrity and fairness. Simultaneously, I assume, also judging from my own experiences as an author, mechanisms of self-censorship are at work.

Researchers in the field use social media, currently predominantly Twitter and Instagram, to advertise publications (their own or those of others) and presentations (for

21 Pradeep Chakkarath, for example, has published extensively on the relation of psychology to indigeneity, (post-)colonialism and the importance of cross-cultural research for social science. See, "Pradeep Chakkarath," Academia, n.d., accessed November 13, 2021, https://rub.academia.edu/PradeepChakkarath; Examples for the discussion of African psychologies are Stephen Baffour Adjei, “Conceptualising Personhood, Agency, and Morality for African Psychology," Theory and Psychology 29, no. 4 (2019), accessed October 26, 2021, https://doi.org/ $\underline{10.1177 / 0959354319857473}$ and Kopano Ratele, "Four (African) Psychologies," Theory \& Psychology 27, no 3 (2017), 313-327, accessed October 27, 2021, https:/ / doi.org/10.1177/0959354316684215; I, myself, explored the potential of Kulturpsychologie (cultural-psychology) for the understanding of violence. See, Christian Gudehus, "Gewalt," in Stichwörter zur Kulturpsychologie, ed. Carlos Kölbl and Anna Sieben (Gießen: Psychosozial, 2018), 175-180. 
example, when they attend meetings). As much as the distribution of such contents beyond the usual academic channels is to be appreciated, as much does it entail a further honing in on those people and contents that live up to the requirements of these media channels (e.g., attracting followers and reposts).

All this contributes to a deficit of public discussions that are objective and fair. Roundtables, such as the ones published in the Journal of Perpetrator Research, are examples illustrating how this development can be countered. We need the discussion about explanatory models, methods, and materials. These debates must—and this is a very touchy topic-take place in disregard of the person. It is undoubtably social origin that determines individual preferences as regards topics, methods, and theories-as has impressively been empirically proven, for example, by Pierre Bourdieu a long time ago.22 Yet the devaluation or appreciation of scientific publications must not depend on the question to which authors can be ascribed to. An argument is not good because it is stated by someone to whom I ascribe the same identity features as to myself. Likewise, an argument is not bad only because it is advanced by someone with different features than mine. At a very basic level, science relies on criticism and transparency. For this reason, its rules-such as the quality criteria for the collection, documentation, and analysis of data-can be modified. The reflection of one's own personality has always been part of this. Yet, to say that a member of group $X$ (and who determines who is a member of which group?) must not make a statement on issue $\mathrm{Y}$ or that statements made by members of group $\mathrm{Z}$ must not be criticized is, I believe, out of the question. A good/bad example for this is German historical research on the holocaust; because for some time, it claimed that Jews cannot write about this topic because they were too strongly affected by it. I therefore pledge for a culture of criticism that is subject-related, fair, and not identitarian.

I have combined the criticism uttered here with specific suggestions because I am convinced that it is not enough to problematize. It is thus only a first, easily taken step to point out limits in research processes. A second, far more difficult one consists in realizing the resultant implications. My criticism is also necessarily limited to what I know, the languages I understand, the authors I have read, the explanatory models of the disciplines I have acquainted myself with. I plainly do not know what I do not know. For this reason, I specify my appeal. I would like to open up the field and at the same time preserve central features of science of a so-called Western provenance. These are transparency, criticism, and therefore constant development. Simultaneously, I do not claim to be the first or even the only one to argue for these points. I simply share the observations I have made when reading for GSP and beyond.

\section{Bibliography}

Abbott, Andrew. Time Matters: On Theory and Methods. Chicago: The University of Chicago Press, 2001.

Academia. "Pradeep Chakkarath." n.d. Accessed November 13, 2021. https:// rub.academia.edu/PradeepChakkarath.

Adjei, Stephen Baffour. "Conceptualising Personhood, Agency, and Morality for African Psychology." Theory and Psychology 29, no. 4 (2019), 484-505. Accessed October 26, 2021. https:// doi.org/10.1177/0959354319857473.

Asch, Solomon E. "Studies of Independence and Conformity: I. A Minority of One Against a Unanimous Majority." Psychological Monographs: General and Applied 70, no. 9 (1956), 1-70.

Bourdieu, Pierre. Homo Academicus. Paris: Les Éditions de Minuit, 1984.

Büchenbacher, Katrin. "Universitäten brauchen China-Kompetenz, keine Konfuzius-Institute." Neue Zürcher Zeitung, October 27, 2021. Accessed October 27, 2021. https://www.nzz.ch/ meinung/europaeische-universitaeten-brauchen-keine-konfuzius-institute-ld.1652328? mktcid=nled\&mktcval=164 2021--10-28\&kid=nl164 2021-10-27\&ga =1\&trco=.

Byford, Jovan and Cristian Tileagă. "Social Psychology, History, and the Study of the Holocaust: The Perils of Interdisciplinary 'Borrowing.'" Peace and Conflict: Journal of Peace

22 Pierre Bourdieu, Homo Academicus (Paris: Les Éditions de Minuit, 1984). 
Psychology 20, no. 4 (2014), Advance online publication, 349-364. Accessed November 1, 2021. http://dx.doi.org/10.1037/pac0000054.

Cheung, Maria, Torsten Trey, David Matas, and Richard An, "Cold Genocide: Falun Gong in China." Genocide Studies and Prevention 12, no. 1 (2018), 38-62. Accessed October 5, 2021. https://doi.org/10.5038/1911-9933.12.1.1513.

Freedom House. "Out of Sight, Not out of Reach. The Global Scale and Scope of Transnational Repression. Case Studies: China." Accessed October 27, 2021. https://freedomhouse.org/sites/default/files/2021-02/ FH TransnationalRepressionReport2021 rev020221 CaseStudy China.pdf.

Gudehus, Christian. "Appropriations of Social Psychological Studies in Genocide Research Exemplified by References to Solomon E. Asch's Study of Independence and Conformity." Journal of Genocide Research. doi:10.1080/14623528.2021.1987039.

--------. "Gewalt." In Stichwörter zur Kulturpsychologie, edited by Carlos Kölbl and Anna Sieben, 175-180. Gießen: Psychosozial, 2018.

-----.. "On the Significance of the Past for Present and Future Action." In Theorizing Social Memories: Concepts and Contexts, edited by Gerd Sebald and Jatin Wagle, 84-97 London: Routledge, 2016.

Henrich, Joseph, Steven J. Heine, and Ara Norenzayan. "The Weirdest People in the World?." Behavioral and Brain Science 33, no. 2-3 (2010), 61-83.

Hoebel, Thomas and Wolfgang Knöbl, Gewalt erklären! Plädoyer für eine entdeckende Prozesssoziologie. Hamburg: Hamburger Edition, 2019.

International Association of Genocide Scholars (IAGS). "Resolutions." n.d. Accessed November 7, 2021. https://genocidescholars.org/publications/resolutions/.

Joas, Hans and Wolfgang Knöbl. Social Theory: Twenty Introductory Lectures. Cambridge: Cambridge University Press, 2009.

Klein, Richard A., Michelangelo Vianello, Fred Hasselman, Byron G. Adams, Jr., Sinan Alper, Mark Aveyard et al. "Many Labs 2: Investigating Variation in Replicability Across Sample and Setting," Advances in Methods and Practices in Psychological Science 1, no, 4 (2019), doi:10.1177/2515245918810225.

Le Texier, Thibault. "Debunking the Stanford Prison Experiment." American Psychologist 74, no. 7 (2019), 823-839.

Marková, Ivana. "Questioning Interdisciplinarity: History, Social Psychology, and the Theory of Social Representation." In Psychology and History: Interdisciplinary Explorations, edited by Christian Tileagă and Jovan Byford, 109-126. Cambridge: Cambridge University Press, 2014.

Perry, Gina. Behind the Shock Machine: The Untold Story of the Notorious Milgram Psychology Experiments. New York: The New Press, 2013.

Popitz, Heinrich. "Social Norms." Genocide Studies and Prevention 11, no. 2 (2017), 3-12, Accessed October 5, 2021. http:/ / doi.org/10.5038/1911-9933.11.2.1552.

. "Der Begriff der sozialen Rolle als Element der soziologischen Theorie." In Heinrich Popitz Soziale Normen, edited by Friedrich Pohlmann, 117-157. Frankfurt am Main: Suhrkamp, 2006.

Ratele, Kopano. “Four (African) Psychologies." Theory \& Psychology 27, no 3 (2017), 313-327. Accessed October 27, 2021. https:/ / doi.org/10.1177/0959354316684215.

Scholars at Risk. "China: Revoke Sanctions on International Scholars and Respect Free and Open Scholarly Inquiry." Accessed November 7, 2021. https:/ / www.scholarsatrisk.org/ 2021/05/china-revoke-sanctions-on-international-scholars-and-respect-free-and-openscholarly-inquiry/.

Smith Finley, Joanne. "Why Scholars and Activists Increasingly Fear a Uyghur Genocide in Xinjian." Journal of Genocide Research 23, no. 3 (2021), 348-370. Accessed November 13, 2021. https: / / doi.org/10.1080/14623528.2020.1848109.

Turdush, Rukiye and Magnus Fiskesjö. "Dossier: Uyghur Women in China's Genocide." Genocide Studies and Prevention 15, no. 1 (2021), 22-43. Accessed November 13, 2021. https://doi.org/10.5038/1911-9933.15.1.1834. 